3. Ravdin PM, Siminoff IA, Harvey JA. Survey of breast cancer patients concerning their knowledge and expectations of adjuvant therapy. J Clin Oncol 1998; 16: 515-521.

4. Blanchard CG, Labreque MS, Ruckdeschel JC, et al. Information and decision-making preferences of hospitalised cancer patients. Soc Sci Med 1998; 27: 1139-1145.

5. Degner LF, Kristjanson LJ, Bowman D, et al. Information needs and decisional preferences in women with breast cancer. JAMA 1997; 277: 1485-1492.

6. Gattelari M, Butow P, Tattersall MHN. Sharing decisions in cancer care (unpublished).

7. Wiggers JH, O.Donovan KO, Redman S, Sanson-Fisher RW. Cancer patient satisfaction with care. Cancer 1990; 66: 610616.

8. Audit Commission. What seems to be the matter: communication between hospitals and patients. NHS Report 12. London: Her Majesty's Stationery Office, 1993.

9. Vincent et al. Lancet 1994; 343: 1609-1613.

10. Derogatis LR, et al. The prevalence of psychiatric disorders among cancer patients. JAMA 1983; 249: 751-57.

11. Spiegal D. Cancer and depression. Br J Psychiatry 1996; 30(Suppl): 109-16.

12. Reiger DA, Hirschfeld RM, Goodwin FK et al. The NIMH depression awareness, recognition and treatment program: Structure, Aims and scientific basis. American Journal of Psychiatry 1988; 145: 1351-1357.

13. Ford S, Fallowfield L, Lewis S. Can oncologists detect distress in their out-patients? Br J Cancer 1994; 70: 767-70.

14. Maguire P, Tait A, Brooke M, et al. Effect of counselling on the psychiatric morbidity. Br Med J 1980; 281: 1454.

15. Newell S, Sanson-Fisher RW, Girgis A, Bonaventura A. How well do medical oncologists' perceptions reflect their patients' problems? Cancer 1998; 83: 1640-51.

16. Brown RF, Butow P, Dunn S. and Tattersall M. Oncologists' reactions to cancer patients' verbal cues (unpublished).

17. Neuling SJ and Winefield HR. Social support and recovery after surgery for breast cancer: correlates of supportive behaviours by family, friends and surgeon. Soc Sci Med 1988; 27: 385-92.
18. Ley P, Bradshaw PW, Kincey J, Atherton ST. A method for increasing patients recall of information presented to them. Psychological Medicine 1973; 3: 217-220.

19. Fallowfield LJ, Hall A, Maguire GP, Baum M. Psychological outcomes of difference treatment policies in women with early breast cancer outside a clinical trial. BMJ 1990; 301: 575580.

20. Roberts CS, Cox CE, Reintgen DS, Baile WF, Gibertini M. Influence of physician communication on newly diagnosed breast patients' psychologic adjustment and decision-making. Cancer 1994; 74: 336-341.

21. Australia's First National Breast Cancer Conference for Women. 1998 Actions recommended by women with breast cancer for the benefit of the Australian community. www.nbcc.org.au/pages/info/cpubs/makediff/reports.htm.

22. Ramirez AJ, Graham J, Richards MA et al. Mental health of hospital consultants Lancet 1996; 347: 724-728.

23. Girgis A, Sanson-Fisher RW, McCarthy WH. Communicating with patients: Surgeons' perceptions of their skills and need for training. Aust NZ J Surgery 1997; 67: 775-780.

24. Meyer TJ and Mark MM. Effects of psychosocial interventions with adult cancer patients. Health Psychology 1995; 4: 101-8.

25. Sheard T, et al. The effect of psychological interventions on anxiety and depression. Br J Cancer 1999: 80(11): 1770-80.

26. National Health and Medical Research Council and National Breast Cancer Centre. Psychosocial clinical practice guidelines: information, support and counselling for women with breast cancer. Canberra: AGPS, 2000.

27. Baile WF, Lenzi R et al. Improving physician-patient communication in cancer care. J Cancer Ed 1997; 12(3): 16673.

28. Fallowfield L, Lipkin M, Hall A. Teaching senior oncologists communication skills. J Clin Oncol 1998; 16(5): 1961-8.

29. Rutter DR, Iconomou G, Quine L. Doctor-patient communication and outcome. Psychology \& Health 1996; 12: 57-71. 席

\title{
PSYCHOSOCIAL GUIDELINES IN CANCER CARE AND SUPPORT
}

\section{Jane Turner}

\section{Department of Psychiatry}

University of Queensland

The increasing demands of consumers for attention to the psychosocial aspects of care has been acknowledged with the release of clinical practice guidelines for the psychosocial care of women with breast cancer. This article describes the development of the Psychosocial Clinical Practice Guidelines: information, support and counselling for women with breast cancer by the National Breast Cancer Centre, which have been endorsed by the National Health and Medical Research Council. ${ }^{1}$ These Guidelines provide a valuable model for the promotion of psychosocial care for all patients with cancer.

\section{BACKGROUNDTOTHE DEVELOPMENT OFTHE GUIDELINES}

Approximately 10,000 Australian women are diagnosed with breast cancer every year. In addition to the demands of their physical treatment, these women must contend with complex practical, emotional, and psychological demands. Between 2030 per cent of women with breast cancer experience a reduction in their quality of life due to emotional distress and a disruption of their roles; ${ }^{2}$ however, emotional support and access to appropriate information remain major unmet needs of Australian cancer patients. $^{3}$ The depth of community feeling about the emotional effects of breast cancer entered the public 
domain with the 1995 publication Report on the management and treatment of breast cancer, ${ }^{4}$ which was based on an inquiry conducted by the House of Representatives Standing Committee on Community Affairs. The Report concluded:

'Despite the proven high incidence of serious psychosocial morbidity in breast cancer patients, in Australia at least very little has been done to either investigate the extent and severity of that morbidity or to provide a suitable means of addressing it either as a preventive measure or as a therapeutic measure. ${ }^{4}$

\section{NATIONAL BREAST CANCER CENTRE INITIATIVES}

In response to these community concerns about the human costs of breast cancer, the Commonwealth Government opened the National Health and Medical Research Council National Breast Cancer Centre in 1995. A key goal of the Centre was to ensure that all women with breast cancer receive adequate psychosocial, physical and practical support. The Psychosocial Working Group (now Psychosocial Expert Advisory Group) was convened to assist in achieving this goal. This multi-disciplinary group undertook to identify the extent of the emotional effect of breast cancer and the ways in which this burden could be reduced. Given the perception of many that psychosocial interventions lack scientific credibility, it was considered crucial that any report be based on the best available evidence. Thus, the Group commissioned seven comprehensive and systematic reviews of the breast cancer literature. Although in many cases there is evidence specifically related to breast cancer, in some cases the evidence was generic to all cancers-for example, being given the diagnosis of cancer. All reviews examined in detail the design and quality of studies, and rated the level of evidence according to the standards advocated by the NHMRC. ${ }^{5}$ The Group also engaged in extensive consultation with consumers, and health professionals involved in all aspects of cancer care, to ensure that any recommendations made had clinical relevance and utility. A draft document detailing recommendations about the psychosocial care of women with breast cancer was distributed for public consultation, and the feedback from this was incorporated into the guidelines along with comments from relevant experts, representatives of the professional colleges, and consumer representatives.

\section{FROM EVIDENCE AND CONSULTATIONTO GUIDELINES}

Clinical practice guidelines were developed on the basis of the best available evidence and extensive consultation. The Guidelines were piloted in 1998 as part of a multicentred trial of a specialist breast nurse 'model of care' at treatment centres in Melbourne, Perth, Adelaide, and Dubbo. Aspects of the Guidelines were also incorporated into communication skills training programs for senior oncologists delivered during 1998 and 1999. In 1997, the opinion of the National Breast Cancer Centre Consumer Advisory Group was obtained to supplement feedback from the pilot testing. A final draft of these guidelines Psychosocial Clinical Practice Guidelines: Providing information, support and counselling for women with breast cancer was endorsed by the NHMRC in December 1999, and were officially launched in February 2000.

\section{CONTENT AND STYLE OF THE GUIDELINES}

The Guidelines promote integration of psychosocial care into all aspects of the care of women with breast cancer, and as such are designed for use by all members of the treatment team. Endorsement by the NHMRC confirms that psychosocial care is no longer an 'optional extra'.

In addition to background information about emotional morbidity, there are specific recommendations about the provision of information, including breaking the news of the diagnosis of breast cancer, recurrent or metatastic disease. Many of the recommendations are based on Level I evidence (that is, evidence obtained from a systematic review of all relevant randomised control trials) and Level II evidence (that is, evidence obtained from at least one properly designed randomised control trial). For example, providing appropriate detailed information promotes understanding and increases the psychological wellbeing of women. ${ }^{6}$ Similarly, providing women with information about a procedure they are about to undergo reduces emotional distress and improves psychological and physical recovery. ${ }^{7}$ Detailed evidence is also presented about the emotional impact of practical needs and financial issues. Evidence is cited for the role of specialist breast nurses in the provision of information, emotional support, and maintaining continuity of care. ${ }^{8}$

The Guidelines highlight the benefit of discussing feelings with a member of the treatment team or counsellor, ${ }^{5}$ and the efficacy of interventions to treat psychological distress. ${ }^{9,10}$ One of the strengths of the Guidelines is the clear approach to the identification of emotional distress. Health professionals whose training in this area is limited may feel concerned about compounding the distress of patients by broaching psychosocial issues. However, the Guidelines offer practical examples of the ways in which emotional concerns can be explored. In addition, the Guidelines challenge the notion that being depressed or anxious in response to a devastating diagnosis is always a 'normal' reaction, detailing approaches to the diagnosis and treatment of anxiety and depression. Identification of those at increased risk of psychological distress may allow for early detection and treatment, or even the prevention of disorder. ${ }^{1}$

\section{DISSEMINATION AND IMPLEMENTATION}

Translating evidence-based clinical practice guidelines into routine clinical care is not simple. Evidence suggests that factors that promote increased uptake include 
endorsement by professional organisations, ${ }^{11}$ and the valuable role of clinical opinion leaders. ${ }^{12}$ With this in mind, copies of the Guidelines have been disseminated to the key professional colleges seeking their endorsement, and copies sent to breast surgeons, medical and radiation oncologists, and consultationliaison psychiatrists have been accompanied by a 'champion letter' written by a prominent member of the respective professional group. Copies have also been distributed to cancer treatment centres, palliative care units, and divisions of general practice.

Many of the recommendations of the Guidelines do not require new infrastructure, but they do require enhanced communication skills and awareness of psychosocial issues. The National Breast Cancer Centre has taken a leadership role in the promotion of communication skills training throughout Australia, and key sections of the Guidelines have been incorporated into communication skills training for oncologists and surgeons. This 'hands on' delivery of information with active involvement, and discussion with colleagues is felt by doctors to be most likely to have an effect. ${ }^{13}$

Clinical practice guidelines have their detractors. Barriers to uptake include the perception that guidelines reduce clinical autonomy, and advocate 'cookbook' medicine. ${ }^{14}$ Resource issues and time constraints have also been cited, ${ }^{15}$ and an Australian survey of surgeons revealed concerns about medicolegal implications of clinical practice guidelines, ${ }^{16}$ although it appears unlikely that clinical practice guidelines will promote litigation. ${ }^{17}$

\section{CONCLUSION}

Health professionals who work with patients with cancer have long felt concerned about the best ways to assist their patients to cope with the disease. Although the implementation of these evidence-based guidelines poses challenges, there is the very real potential to improve health care outcomes, including a reduction in psychological morbidity, improved wellbeing and patient satisfaction with care.

\section{REFERENCES}

1. National Health and Medical Research Council and National Breast Cancer Centre. Psychosocial clinical practice guidelines: information, support and counselling for women with breast cancer. Canberra: AGPS, 2000.

2. Irvine D, Brown B, Crooks D, Roberts J, Browne G. Psychosocial adjustment in women with breast cancer. Cancer 1991; 67: 1097-117.

3. Sanson-Fisher R, Girgis A, Boyes A, Bonevski B, Burton L, Cook $\mathrm{P}$ et al. The unmet supportive care needs of patients with cancer. Cancer 2000; 88(1): 226-237.

4. House of Representatives Standing Committee on Community Affairs. Report of the Management and Treatment of Breast Cancer Canberra: AGPS, 1995; 34.

5. Quality of Care and Health Outcomes Committee, National Health and Medical Research Council. Guidelines for the development and implementation of clinical practice guidelines. Canberra: AGPS, 1995.

6. Devine EC, Westlake SK. The effects of psychoeducational care provided to adults with cancer: meta-analysis of 116 studies. Oncology Nursing Forum 1995; 22(9): 1369-1381.

7. Johnston M, Voegele C. Benefits of psychological preparation for surgery: A meta-analysis. Annals of Behavioural Medicine 1993; 15: 245-256.

8. McArdle JMC, George WD, McArdle CS, et al. Psychological support for patients undergoing breast cancer surgery: a randomised study. BMJ 1996; 312(7034): 813816.

9. Meyer TJ, Mark MM. Effects of psychosocial interventions with adult cancer patients: a meta-analysis of randomised experiments. Health Psychology 1995; 14(2): 101-108.

10. Sheard T, Maguire P. The effect of psychological interventions on anxiety and depression in oncology: results of two metaanalyses. British Journal of Cancer 1999; 80(11): 1770-80.

11. Curry SJ. Organization interventions to encourage guideline implementation. Chest 2000; 118: 40S-46S.

12. Borbas C, Morris N, McLaughlin B, Asinger R, Gobel F. The role of clinical opinion leaders in guideline implementation and quality improvement. Chest 2000; 118: 24S-32S.

13. Newton J, Knight D, Woolhead G. General practitioners and clinical guidelines: a survey of knowledge, use and beliefs. British Journal of General Practice 1996; 46: 513-517.

14. Cabana MD, Rand CS, Powe NR, Wu AW, Wilson MH, Abboud P-A, Rubin HR. Why Don't Physicians Follow Clinical Practice Guidelines? JAMA 1999; 282: 1458-1465.

15. Basinski ASH. Evaluation of Clinical Practice Guidelines. Can Med Assoc J 1995; 153: 1575-1581.

16. Carrick SE, Bonevski B, Redman S, Simpson J, SansonFisher RW, Webster F. Surgeons' opinions about the NHMRC clinical practice guidelines for the management of early breast cancer. MJA 1998; 169: 300-305.

17. Dwyer P. Legal implications of clinical practice guidelines. MJA 1998; 169: 292-293. W 